\title{
A New Compact and Miniaturized GCPW-fed Slotted Rectangular Antenna for Wideband UHF FIRD Applications
}

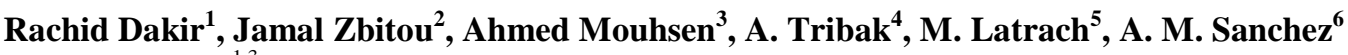 \\ 1,3 IM2I Laboratory, FST Settat University Hassan 1st, Settat, Morocco \\ ${ }^{2}$ MEET Laboratory, FST Settat University Hassan 1st, Settat, Morocco \\ ${ }^{4}$ National Institute of Posts and Telecommunications, Rabat, Morocco \\ ${ }^{5}$ RF \& Hyper group, ESEO, Angers, France \\ ${ }^{6}$ DICOM Laboratory, Cantabria University Santander, Spain
}

\section{Article Info \\ Article history: \\ Keyword: \\ GCPW \\ Miniaturized \\ Shaped \\ Slot \\ UHF RFID}

Received Nov 9, 2016

Revised Mar 1, 2017

Accepted Mar 14, 2017

\begin{abstract}
This paper presents the development of a new miniaturized and compact GCPW-fed slotted rectangular antenna structure reader for wideband UHF RFID applications. The optimized proposed antenna is suitable to operate a large frequency-band range from $0.8 \mathrm{GHz}$ to $1.3 \mathrm{GHz}$ with a bandwidth of $500 \mathrm{MHz}$ with a return loss less than $-10 \mathrm{~dB}$. The antenna is based on a $1.6 \mathrm{~mm}$ thickness FR4 epoxy substrate with a reduce dimensions compared to the simple rectangular antenna and size of proposed antenna is $47 * 40 \mathrm{~mm} 2$. The new design consists of a compact rectangular patch with symmetric Ushaped slots and I-shaped include a partial ground plan and fed by 50 Grounded coplanar line. The antenna parameters have been investigated and optimized by using CST Microwave Studio. To validate the CST Microwave Studio results before the antenna achievement, we have conducted another study by using ADS. The final circuit achieved, measured and validated. Experimental results show that the proposed antenna has good radiation characteristics and operating in UHF-RFID applications.
\end{abstract}

Copyright $@ 2017$ Institute of Advanced Engineering and Science. All rights reserved.

\section{Corresponding Author:}

Rachid Dakir,

Faculty of Sciences and Techniques

University Hassan 1st,

University Complex Casablanca road, Km 3.5, B.P : 577 Settat, Morocco.

Email:dakir_fsts@hotmail.com

\section{INTRODUCTION}

In recent years, Much attention has been devoted to the optimization of reader antenna design for UHF-RFID systems, because of more and more practical applications in industrial services, such as automatic retail item management, warehouse management, access control system, electronic toll collection, etc. This is because the UHF band can provide high data transfer rate and broad readable range [1-3]. In spite of the fact that these applications are important around the world, diverse districts have distinctive administrative standards for UHF RFID frameworks. In China the UHF-RFID bands are 840-845 MHz and 920-925 MHz, while for North America, Europe $902-928 \mathrm{MHz}, 865-868 \mathrm{MHz}$ are used respectively, while for Japan up till 2018 two bands can be used 916-924MHz and 950-956MHz. So for an UHF RFID item to work all inclusive it should be reconfigurable or has enough band to cover the whole UHF RFID band (840-960 $\mathrm{MHz}$ ). This adds a challenge in designing a global UHF RFID antenna. The RFID reader antenna is one of the important components in RFID system and its capability will determine the performance of whole RFID system [4]. For the applications involving item-level management, a RFID handheld reader plays an important role owing to its advantages of compactness and maneuverability. The growing demand for small and compact wireless devices has increased the need for small antenna that can be integrated while providing acceptable overall performance [5]. Many broadband UHF-RFID reader antennas have been 
proposed in literature [6]. At present, miniaturized reader antenna therefore becomes a research trend in RFID system. Usually there are many ways to realize miniaturization, such as shorting circuit between patch and ground plane [7], and increasing relative dielectric constant of substrate [8].

In this paper, a new compact GCPW broadband antenna for UHF RFID applications is proposed. Details of the antenna design are described, a parametric study is conducted to examine the effect of the slot dimensions and the final dimensions of the antenna are stated and both the simulated and measured results are presented and discussed.

\section{ANTENNA CONFIGURATION AND PERFORMANCES}

The schematic configuration of the proposed planar GCPW-fed slotted rectangular antenna is shown in Figure 1. This antenna is fabricated on a FR4 epoxy substrate with a relative permittivity 4.4 , and a thickness of $1.6 \mathrm{~mm}$ and 0.025 for loss tangent. In order to obtain miniaturized antenna with optimum impedance bandwidth for UHF-RFID applications, a parametric analysis is done by some variations of the dimensions on the rectangular shaped of a center ground plane. Simple CPW is used for broadband antenna reference feeding which gives broadband behavior. To provide $50 \Omega$ impedance GCPW fed and adapted for specific applications.
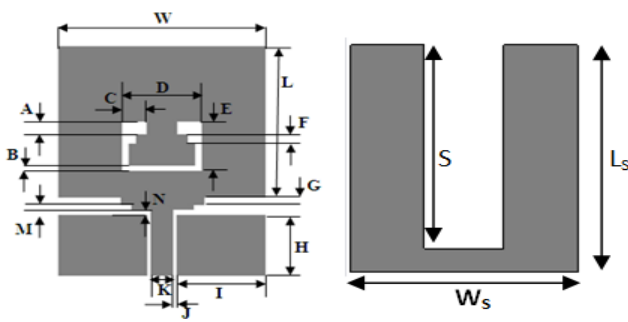

Figure 1. Geometry of the CPW antenna

Table 1. Optimized dimensions of the designed antenna (unit :mm)

\begin{tabular}{ccccccc}
\hline Parameter & $\mathrm{A}$ & $\mathrm{B}$ & $\mathrm{C}$ & $\mathrm{D}$ & $\mathrm{E}$ & $\mathrm{F}$ \\
\hline Value & 2.5 & 1 & 3.5 & 11.5 & 9.5 & 2 \\
Parameter & $\mathrm{G}$ & $\mathrm{H}$ & $\mathrm{I}$ & $\mathrm{J}$ & $\mathrm{K}$ & $\mathrm{M}$ \\
Value & 1 & 12.5 & 12.9 & 0.5 & 3.2 & 0.5 \\
Parameter & $\mathrm{LS}$ & $\mathrm{WS}$ & $\mathrm{P}$ & $\mathrm{R}$ & $\mathrm{S}$ & \\
Value & 47 & 40 & 12 & 16 & 45 & \\
\hline
\end{tabular}

The aim of this study is to develop the compact UHF RFID reader antenna compared a classical rectangular antenna.

The antenna reference is based on a CPW rectangular monopole antenna structure with U-slot [9]. It has an impedance matching BW over $20 \%$ with a return loss less then $-10 \mathrm{~dB}$ and covers the global SHF RFID band $(2.2-2.7 \mathrm{GHz})$. By adding the ground plane with I-shaped slot inverted and optimized. The final antenna optimized is suitable for small or handheld UHF RFID readers and the final are listed in Table 1. To start the design, series of optimizations is conducted by using electromagnetic simulations.

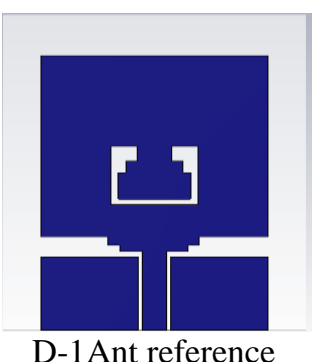

D-1Ant reference

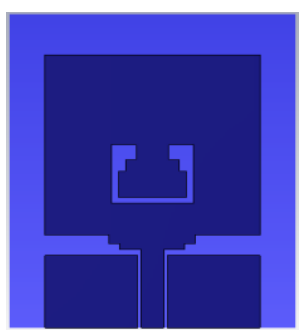

D-2

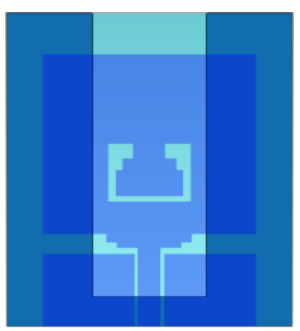

D-3

Figure 2. Design evolution of the proposed antenna 
The goal of this study is to design a new compact and miniaturized antenna structure for UHF RFID applications. The design evolution of the proposed antenna is presented in Figure 2. The conception of the planar antenna capabilities is due to the large frequency resonances introduced by combining the optimizations of the dimensions GCPW-feed line width and cutting slot shaped on the ground plane antenna. Therefore, Figure 3 shows the simulated return losses for successive cases of the conception of the final antenna. From Figure 3, we can clearly see that the proposed antenna is designed through two steps. Firstly, for a reference rectangular plane adapted to a large frequency band ranging from $2.2 \mathrm{GHz}$ to $2.7 \mathrm{GHz}$ for $\mathrm{SHF}$ RFID Applications, the antenna geometry was modified to develop the miniaturized and compact antenna adapted the bandwidth for UHF RFID frequency band. Therefore, by adding a ground plane to the bottom of the antenna, it turns to be GCPW fed antenna with a disapted bandwidth.

Secondly, after cutting the ground plane and adding the I-Shaped with optimized dimensions, the matching input impedance of the final antenna structure is achieved in large frequency band $0.8-1.3 \mathrm{GHz}$ with a return loss less than $-10 \mathrm{~dB}$. Before the achievement of the antenna and to compare CST results of another simulator, we have used ADS which is based on Method of Moments (MoM). After the simulation, the following result is shown in Figure 4. The Table 2 shows the comparison of of gain and dimensions of the final proposed antenna with pulished literature UHF RFID reader antenna structures. The proposed antenna yield a compact and miniatiruzed dimansions occupies only $47 \times 40 \mathrm{~mm}^{2}$. Which is very compact than other geometries in the existing literatures and the defect using a partial ground plane also enhaces the miniatiruzation of the proposed design.

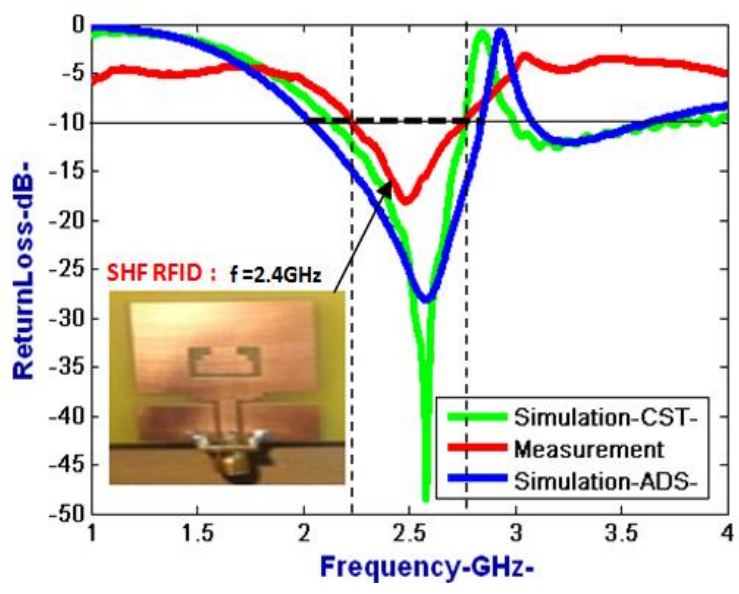

(a) Antenna reference

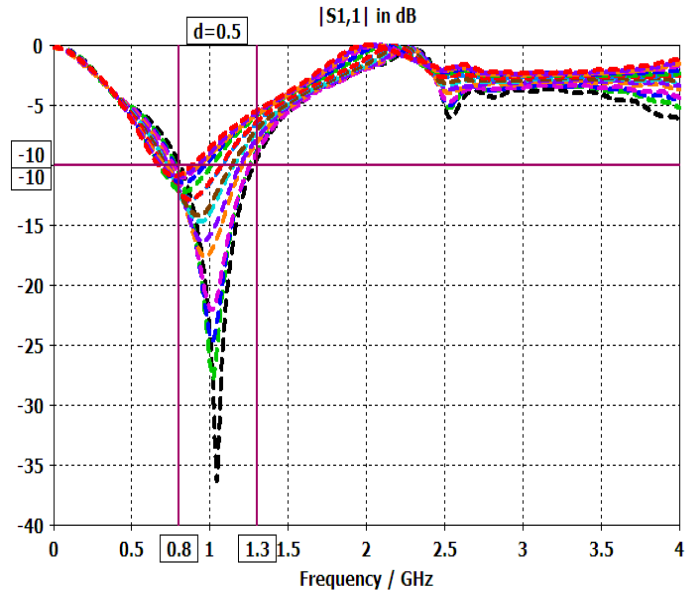

(b)

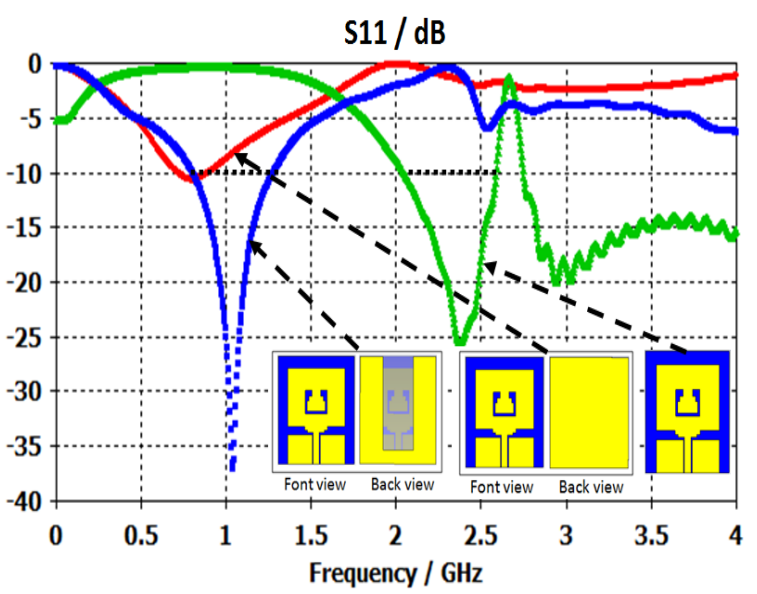

(c)

Figure 3. The return loss vs frequency of the proposed antenna for different cases on CST 


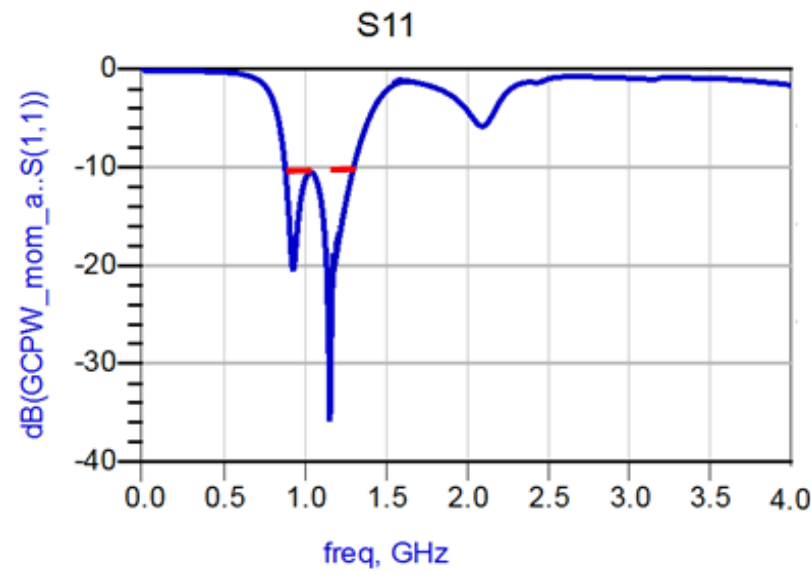

Figure 4. The return loss vs frequency of the proposed antenna in ADS

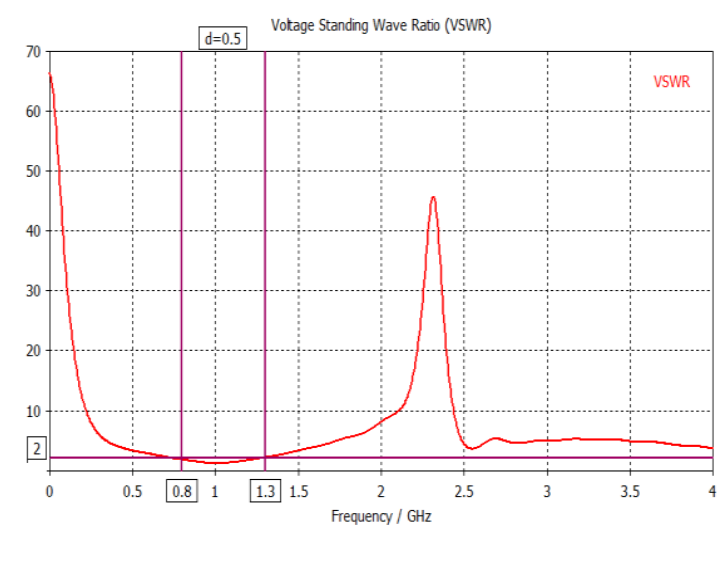

Figure 5. VSWR vs frequency

Figure 5. exhibits the simulated Voltage Standing Wave Ratio (VSWR) versus frequency of the final proposed antenna structure. It is noticed that the VSWR less than 2 for the frequencies throughout matching band. The variation of the proposed antenna gain within the operating frequency band is calculated and displayed in Figure 6. The proposed antenna gain is more than $3.2 \mathrm{dBi}$ at $0.9 \mathrm{GHz}$ and yield simulated peak gain is about $5.7 \mathrm{dBi}$ which is sufficient for present and yield wireless communication standard applications which bandwidth ranging from to $0.8 \mathrm{GHz}$ to $1.3 \mathrm{GHz}$.

Figure 7 gives full details about the simulated surface current distribution of the proposed antenna at $0.9 \mathrm{GHz}, 1 \mathrm{GHz}$ and $1.1 \mathrm{GHz}$. It is observed that the surface currents are highly concentrated around the shaped slot and radiator patch for all frequencies.

Table 2. Comparison of size of proposed antenna with existing literatue

\begin{tabular}{cc}
\hline Published literatures & Total size $\left(\mathrm{mm}^{2}\right)$ \\
\hline Proposed antenna & $47 \times 40$ \\
Antenna classical & $114.7 \times 79.6$ \\
{$[10]$} & $65 \times 65$ \\
{$[11]$} & $150 \times 150$ \\
{$[12]$} & $139 \times 139$ \\
{$[13]$} & $108.3 \times 86.3$ \\
{$[14]$} & $120 \times 120$ \\
\hline
\end{tabular}

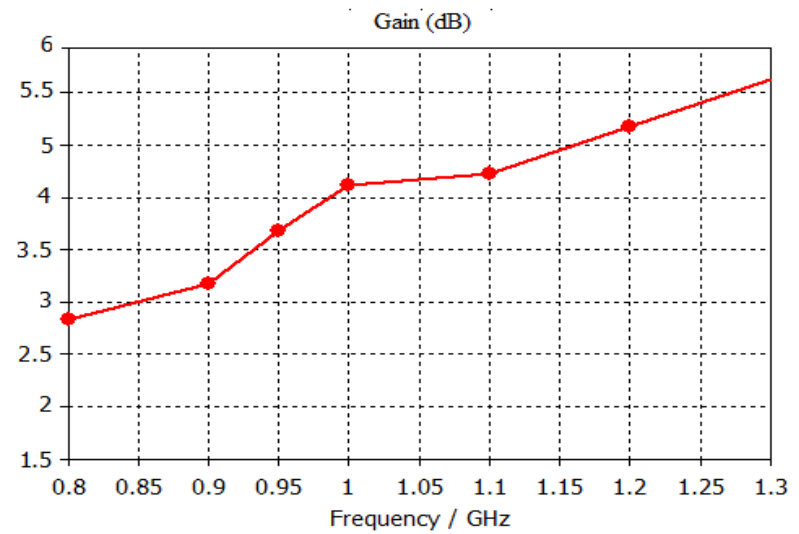

Figure 6. Gain vs Frequency 

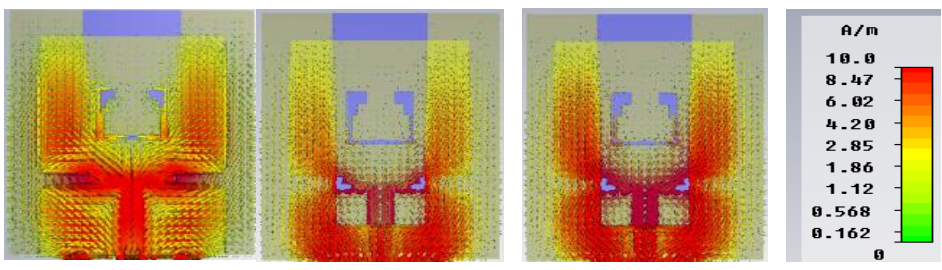

Figure 7. Simulated Surface current distribution of the final proposed antenna at (a) $0.9 \mathrm{GHz}$, (b) $1 \mathrm{GHz}$ and (c) $1.1 \mathrm{GHz}$

\section{ACHIEVEMENT AND MEASUREMENT}

After the comparison of the simulation results in CST and ADS, we have achieved the new compact and miniatiruzde antenna structure by using LPKF machine. The photograph of the fabricated antenna is shown in Figure 8. It was measured in anechoic chamber by using Vectorial Network analyzer VNA R\&S@ZVB20 from Rohde \& Schwarz.
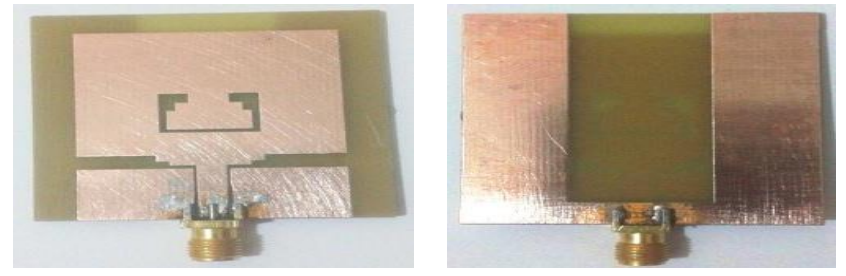

Figure 8 . The fabricated antenna structure

After the conception and the achievement of the proposed antenna structure, we have done the comparison of the different results as shown in Figure 9. As illustrated in Figure 9, we conclude that we have a good agreement between simulation and measurement results. This allows the validation of a new compact reader UFH RFID antenna operating from $0.8 \mathrm{GHz}$ to $1.3 \mathrm{GHz}$. The measured input impedance and bandwidth of the achieved antenna structure is shown in Table 3 .

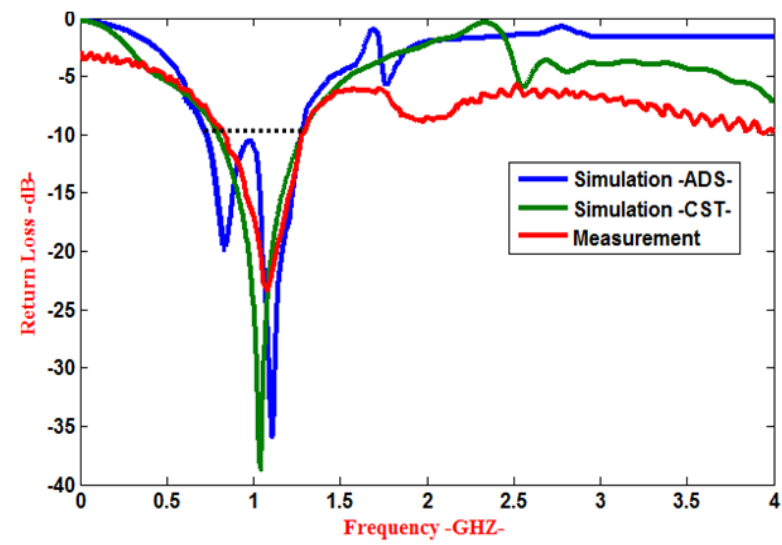

Figure 9. Comparison of simulated and measured return loss

Table 3. The bandwidth of the proposed antenna compared with an antenna reference

\begin{tabular}{lcc}
\hline & Antenna reference & Final antenna structure \\
\hline Dimensions & & $47 * 40 \mathrm{~mm}^{2}$ \\
Bandwidth & $2.2-2.7 \mathrm{GHz}$ & $0.8-1.3 \mathrm{GHz}$ \\
Center Frequency & $2.5 \mathrm{GHz}$ & $1 \mathrm{GHz}$ \\
Impedancebandwidth & $20 \%$ & $50 \%$ \\
\hline
\end{tabular}


The simulated far-field radiation pattern characteristics of the proposed antennas in E-plane and Hplane for two different frequencies $0.9 \mathrm{GHz}, 1 \mathrm{GHz}$ and $1.1 \mathrm{GHz}$ are investigated in Figure 10 . The simulated results show that the good omni-directional patterns in the E-plane and the nearly bidirectional patterns in the H-plane are obtained for all frequency bands.

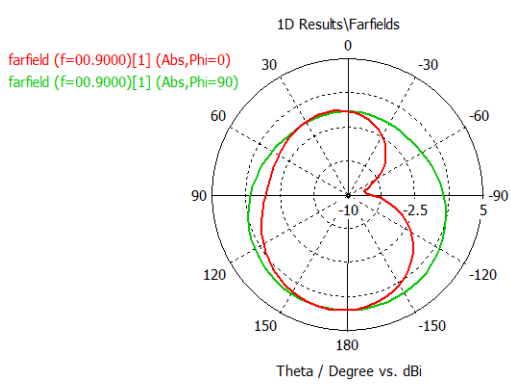

(a)

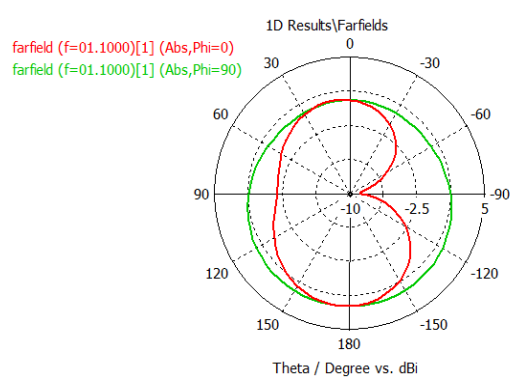

(b)

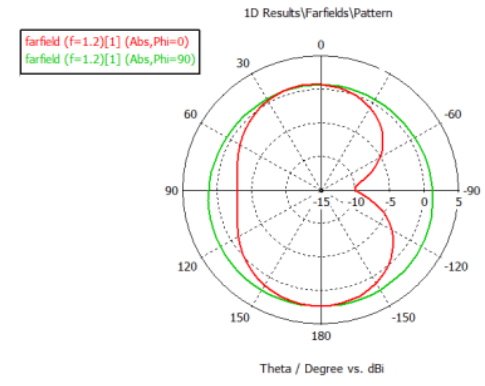

(c)

Figure 10. Measurement and Simulation radiation patterns of the proposed antennae at (a) $0.9 \mathrm{GHz}$, (b) $1.1 \mathrm{GHz}$ and (c) $1.2 \mathrm{GHz}$

\section{CONCLUSION}

In this paper, we presented the development of a new compact and miniaturized structure of microstrip patch antenna intended for wideband UHF RFID applications, which adapted from SHF RFID to UHF RFID systems by using GCPW fed with an optimized U-shaped partial ground plane. It provides optimum impedance matching over entire large frequency band ranging from $0.8 \mathrm{GHz}$ to $1.3 \mathrm{GHz}$ with a return loss less than $-10 \mathrm{~dB}$. This compact antenna design fulfills the requirements of UHF RFID applications but can also be used in other fields of wireless applications.

\section{ACKNOWLEDGEMENT}

We thank Mr. Angel Mediavilla Sanchez Professor in University Cantabria, Spain and Mr. Mohamed Latrach Professor in ESEO, Engineering Institute in Angers, France for allowing us to use all the equipments and softwares available in his laboratory.

\section{REFERENCES}

[1] Eason, B. Noble, and I.N. Sneddon, "On certain integrals of Lipschitz-Hankel type involving products of Bessel functions”, Phil. Trans. Roy. Soc. London, vol. A247, pp. 529-551, April 1955.

[2] J. Clerk Maxwell, A Treatise on Electricity and Magnetism, 3rd ed., vol. 2. Oxford: Clarendon, 1892, pp.68-73.

[3] I.S. Jacobs and C.P. Bean, "Fine particles, thin films and exchange anisotropy", in Magnetism, vol. III, G. T. Rado and H. Suhl, Eds. New York: Academic, 1963, pp. 271-350.

[4] I. Ismail, S.M. Norzeli, UHF RFID Reader Antenna with High Gain, International Journal of Electrical \& Electronic Systems Research (IEESR).

[5] Rong Cao, Shun-Chuan Yu, Wideband Compact CPW-Fed Circularly Polarized Antenna for Universal UHF RFID Reader, IEEE Transactions on Antennas and Propagation,Vol 63, Sept. 2015.

[6] A. Ferchichi, A. Gharsallah, "A Circuit Model to an Encoche Coplanar Antenna for a Radio Frequency Identification TAG”, International Journal of Electrical and Computer Engineering (IJECE), Vol. 3, No. 3, June 2013, pp. 386-391.

[7] A. Sofi, K. Roky, M. Bouhorma, I.H. Baraka, "Novel Antennas for UHF RFID Tags: Design and Miniaturization", Vol. 4, No. 1, Feburary 2014, pp. 75-80.

[8] Abdelhak Ferchichi, Ali Gharsallah. "A Circuit Model to an Encoche Coplanar Antenna for a Radio Frequency Identification". International Journal of Electrical and Computer Engineering (IJECE). 2013, pp. 386-391.

[9] Abdelhak Ferchichi, Gharsallah Ali. "A Novel Small Sierpenski Antennas". International Journal of Electrical and Computer Engineering (IJECE). 2013, pp. 436-440.

[10] R. Dakir, J. Zbitou, A. Mouhsen, A. Tribak, Angel Mediavilla Sanchez and M. Latrach, "Rectangular Planar Antenna Using U-Slot for Bandwidth Improvement", Electrical and Electronic Engineering, pp :118-121, 2013.

[11] I.S. Jacobs and C.P. Bean, "Fine particles, thin films and exchange anisotropy", in Magnetism, vol. III, G.T. Rado and H. Suhl, Eds. New York: Academic, 1963, pp. 271-350. 
[12] Y. Yorozu, M. Hirano, K. Oka, and Y. Tagawa, "Electron spectroscopy studies on magneto-optical media and The Technical Writer's Handbook". Mill Valley, CA: University Science, 1989.

[13] Yanzhong Yu, Yanfei Li and Jingxuan Nie, Miniaturized Design of a CP Antenna for UHF RFID Reader, International Journal of Electronics \& Communication (IIJEC), 2015

[14] Guan-Long Huang, Chow-Yen-Desmond Sim, Chuan-Wei Lin nad Ming-Jie Gao, Low-profile UHF RFID reader antenna with CP radiation and coupled feeding technique, International Journal of RF and Microwave ComputerAided Engineering, 2016

[15] Zhi Ning Chen, Qing Xianming and Hang Leong Chung, A universal UHF RFID reader antenna, IEEE Transactions on Microwave Theory and Techniques.

\section{BIOGRAPHIES OF AUTHORS}

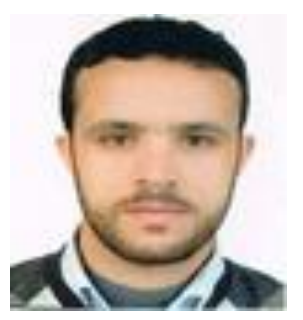

Rachid Dakir was born in 16 February 1982. He received the Master degree in science of computer and systems from the FST University of Hassan 1st in Settat Morocco. He is currently a Phd student in FST university Hassan 1st Settat Morocco. He is involved in the design of microwave hybrid circuits and antennas.

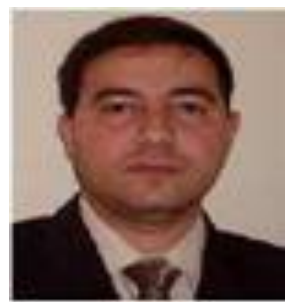

Jamal Zbitou was born in Fes, Morocco, in June 1976. He received the Ph.D. degree in electronics from the University of Nantes, in Nantes, France, in 2005. He is currently an associate Professor of Electronics in FPK University Hassan 1st of Settat in Morocco. He is the head of the team of Telecommunications and Computer Sciences and he is involved in the design of hybrid, monolithic active and passive microwave electronic circuits.

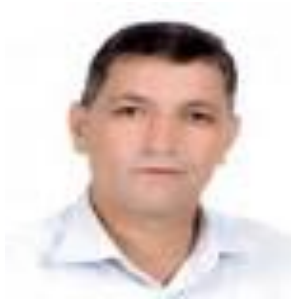

Ahmed Mouhsen was born in May 1960. He received the Ph.D. degree in electronics from the University of Bordeaux I, France. He is currently a Professor of Electronics in FSTSuniversity Hassan 1st Settat Morocco. He is involved in the design of hybrid, active, and passive microwave electronic circuits and digital systems.

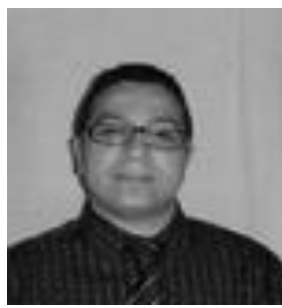

Abdelwahed Tribak was born in Larache, Morocco, in 1981. He received the M.Sc. degree in physics from Abdelmalek Essaadi University, Tétouan, Morocco, in 2006. He received a Master degree in communications engineering from the University of Cantabria, Santander, Spain, in 2008, and received the $\mathrm{PhD}$ of Telecommunication degree in 2011, from the University of Cantabria, Santander, Spain. Since 2006 to 2011, he has been with the Department of Communications Engineering, University of Cantabria. Since 2011 he is a Professor in the National Institute of Poste and Telecommunication, Rabat, Morocco. His main area of activities is microwave circuits and systems; antenna feed subsystems for satellite and radioastronomy applications.

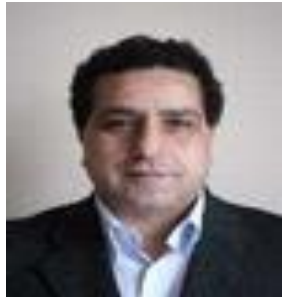

Mohamed Latrach was born in Douar Ksiba, Sless, Morocco, in 1958. He received the Ph.D degree in electronics from the University of Limoges, Limoges, France, in 1990. He is currently a Professor of microwave engineering with the Ecole Suprieure d'Electronique de l'Ouest (ESEO), Angers, France, where his research involves RF and microwaves. His field of interest is the design of hybrid, monolithic active, and passive microwave circuits, metamaterials, LH materials, antennas and their applications in wireless communications, and wireless power transmission. 


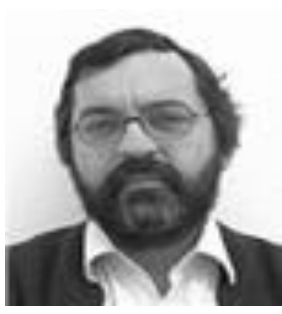

Angel Mediavilla Sanchez was born in Santander, Spain, in 1955. He graduated in 1978 and received the Doctor of Physics (Electronic) degree with honours in 1983, both from the University of Cantabria, Santander, Spain. From 1980 to 1983 he was Ingenieur Stagiere at THOMSON-CSF, France. He is currently head of the Communications Engineering Department at the University of Cantabria. He has a wide experience in the analysis and optimization of nonlinear microwave active devices. His research interests are nonlinear MESFET/HEMT and HBT device modelling with special application to the large signal computer design and new waveguide structures for antenna feed systems. 